\title{
Conselhos de Empresa Europeus militantes? Obstáculos, acordos e boas práticas à luz da experiência portuguesa na VW
}

HERMES AUGUSTO GOSTA

\section{Resumo}

A organização transnacional de trabalhadores apela a distintas configurações institucionais e modos de atuação. Neste texto analisa-se uma dessas formas de organização: os conselhos de empresa europeus (CEEs), estruturas que dão testemunho do modo como os processos de informação e consulta nas empresas de dimensão comunitária podem reforçar a participação laboral transnacional. Baseando-se no impacto setorial dos CEEs em Portugal, este texto valoriza duas dimensões de análise: por um lado, uma dimensão formal e quantitativa associada a uma análise de conteúdos de acordos de CEEs envolvendo representantes de trabalhadores nos setores metalúrgico, químico e financeiro; por outro lado, uma dimensão qualitativa resultante de entrevistas realizadas junto de representantes de trabalhadores em CEEs, de modo a evidenciar boas práticas associadas ao seu funcionamento. Nesse caso, o CEE do grupo Volkswagen merece atenção especial. Argumenta-se que uma transnacionalização laboral efetiva terá sempre de proceder a um trade-off entre uma gestão de obstáculos persistentes e uma maximização de boas práticas emergentes. Assim, sendo uma realidade com "caminho feito", os CEEs continuam a perseguir como até aqui (e porventura ainda mais em contexto de crise económica) o desafio da construção de uma mais coesa identidade laboral transnacional. ${ }^{* *}$

\footnotetext{
*Universidade de Coimbra, Portugal

${ }^{* *}$ Este artigo incorpora contributos de duas pesquisas: por um lado, de uma pesquisa sobre o impacto setorial dos Conselhos de Empresa em Portugal (Costa; Costa, 2014); por outro lado, de um projeto em curso, intitulado "A reconstituição do poder sindical na era da austeridade: três setores
} 
Palavras-chave: Conselhos de empresa europeus. Obstáculos. Acordos setoriais. Portugal. Boas práticas.

\section{Militant European Works Councils? Obstacles, agreements and good practices in the light of the Portuguese experience at VW}

\section{Abstract}

The transnational organization of workers makes use of different institutional configurations and modes of action. This text analyzes one of these forms of organization: European Works Councils (EWCs). These structures reveal how information and consultation processes in EU-scale enterprises can enhance transnational labor participation. Based on the sectoral impact of the EWCs in Portugal, this text emphasizes two dimensions of analysis: on the one hand, a formal and quantitative dimension associated with a content analysis of EWCs agreements involving workers' representatives in the metallurgical, chemical and financial sectors. On the other hand, a qualitative dimension resulting from interviews with workers' representatives in EWCs seeking to show good practices associated with their operation. In this case, the EWC of Volkswagen Group deserves special attention. It is argued that effective labor transnationalization will always have to promote a trade-off between handling persistent obstacles and maximizing emerging good practices. In this sense, even being a reality, whose path is already made, the EWCs proceed in building, as heretofore (and perhaps even more so in the context of economic crisis), a more cohesive transnational labor identity.

Keywords: European Works Councils. Obstacles. Sectoral agreements. Portugal. Best practices.

em análise" (PTDC/IVC-SOC/3533/2014 - POCI-01-0145-FEDER-016808), por mim coordenado e a decorrer no Centro de Estudos Sociais da Universidade de Coimbra entre 2016 e 2018. 
Sociologias, Porto Alegre, ano 19, no 45, mai/ago 2017, p. 82-112

\section{Introdução}

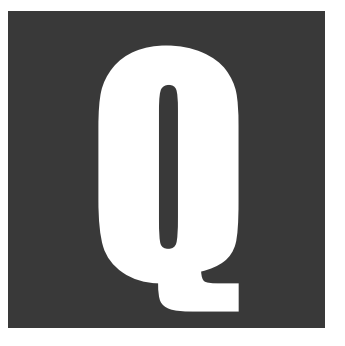

ualquer análise que incida sobre a relevância sociopolítica do sindicalismo não deixará de considerar, porventura como critério prioritário, a questão da representatividade sindical (medida através da sindicalização). $\mathrm{E}$, mesmo admitindo que o cenário internacional está longe de ser uniforme, esse critério nem sempre é usado pelos melhores motivos, pois é recorrentemente apresentado como expressão da crise do sindicalismo. Mas de par com a (quebra da) sindicalização, a questão da autonomia sindical, a relação do sindicalismo com organizações não sindicais, ou os seus apelos internacionalistas são outros desafios que a abordagem do fenómeno sindical suscita (Estanque; Costa; Silva, 2015).

Neste texto concede-se prioridade ao "desafio transnacional". Como é sabido, não se trata de um desafio novo, pois o apelo internacionalista, conjuntamente com a busca de emancipação e homogeneização laboral, esteve na génese do sindicalismo (Hyman, 1999, p. 95; Costa, 2008, p. 42-43). Porém, foi o capital o que melhor se globalizou de modo a superar as "variedades de capitalismo" (Hall; Soskice, 2001), ao passo que o trabalho lidou de forma menos audaz com as "variedades de sindicalismo" (Frege; Kelly, 2004; Gumbrell-McCormick; Hyman, 2013, p. 6-27). Assim, enquanto categoria analítica, o trabalho, fruto das mutações e metamorfoses (Antunes, 2013; Estanque; Costa, 2012) nos espaços nacionais, sentiu maiores dificuldades em congregar esforços no plano transnacional, pelo que é lícito afirmar que o sindicalismo transnacional se configurou como "metáfora adiada" (Costa, 2008).

Essa secundarização da escala transnacional não deve, todavia, ser vista como uma fatalidade, mas antes como um caminho a desbravar. Aliás, convém ter presente que a organização transnacional de trabalhadores é produto de estruturas e estratégias desenhadas de forma multifa- 
cetada e repartidas por vários planos: no plano confederal, com destaque para a Confederação Europeia de Sindicatos e para a Confederação Sindical Internacional; no plano setorial, atendendo ao papel das federações sindicais europeias, ou das federações sindicais globais que identificam problemas específicos de setores; no plano regional, transfronteiriço, no qual os conselhos sindicais inter-regionais abrem caminho para formas de "internacionalismo operário de proximidade" (Costa, 2009), permitindo fazer convergir organizações locais e multisetoriais não apenas sindicais; no plano das empresas multinacionais, em que o diálogo capital-trabalho se concretiza através da celebração de acordos-quadro internacionais entre administrações de multinacionais e federações sindicais globais, ou ainda pela edificação de redes de sindicatos internacionais, por empresa e por setor, pela defesa dos direitos laborais, etc.

O desafio em aberto é o da dedicação e participação em cada um (ou em vários) daqueles planos de análise. Ou seja, seria desejável que o envolvimento em tais planos de análise ocorresse de forma militante ${ }^{1}$, de modo a evidenciar uma forte e permanente disponibilidade de mobilização para lutas e causas sindicais e laborais. Isto é, para formas de participação ativas e não meramente para a observação cómoda, ainda que atenta, das preocupações relacionadas com o mundo do trabalho. Se projetada com êxito para a arena transnacional, tal militância poderá ajudar a superar obstáculos e abrir caminho a boas práticas.

Neste texto, centro a minha análise numa das formas de participação transnacional em que é suposto observar dinâmicas de militância sindical e laboral no quadro das empresas transnacionais: os conselhos de empresa europeus (CEEs). A experiência dos CEEs resulta da Diretiva 94/45/CE

\footnotetext{
1 Ao identificar comportamentos sindicais no plano qualitativo, João Freire (2001, p. 174) distinguiu entre: aderente (simples sócio), militante (que desempenha funções de delegado, que vai a reuniões, etc.), dirigente (que ocupa lugares eleitos dos corpos gerentes associativos), ativista (voluntário), permanente (que trabalha a tempo inteiro no sindicato) e homem de aparelho central (que pertence às federações e/ou à confederação).
} 
(de 22.09.1994), posteriormente revista por meio da Diretiva 2009/38/ CE (de 6.05.2009 e em vigor desde 6.06.2011), a qual tornou possível a constituição de CEEs ou procedimentos de informação e consulta de trabalhadores. Mesmo que não estejamos perante uma temática em que a participação sindical apareça de forma exclusiva, estima-se que cerca de $70 \%$ dos representantes de trabalhadores em CEEs seja proveniente do universo sindical (Waddington, 2011; Costa, 2013; Costa; Costa, 2014).

Do ponto de vista formal, o artigo divide-se em três partes. Na primeira, alude-se ao "claro-escuro" suscitado pela militância em torno dos CEEs. Isto é, por um lado, desafios "expansionistas" que funcionam como efeito de atração, mas, por outro lado, obstáculos que suscitam reservas, deixando transparecer o caminho que há a percorrer. Na segunda parte, analisa-se a faceta formal dos CEEs - traduzida na análise dos acordos de CEEs celebrados e envolvendo representantes de trabalhadores portugueses -, pois daí se vislumbram oportunidades, mas também limitações inerentes à própria "letra da lei" dos acordos. Por fim, levanta-se o véu das "boas práticas", pois é no quadro de ações concretas bem-sucedidas que a transnacionalização laboral se constrói e reforça. E a este respeito, partindo da experiência de representação portuguesa em CEEs no setor metalúrgico, tomam-se como exemplo as conquistas ocorridas no CEE do grupo VW, tendo por referência a fábrica portuguesa da Autoeuropa. Todavia, sem deixar igualmente de alertar para o facto de ser incontornável uma vigilância permanente sobre o exercício das boas práticas.

\section{Os CEEs entre os desafios à militância transnacional e os obstáculos persistentes}

Há mais de duas décadas, em 1994, a Diretiva 94/45/CE representou um importante instrumento jurídico de reforço da representação e 
participação laboral nas multinacionais. Por sinal, um instrumento de democracia laboral (Buschak, 1995), europeização do diálogo social (Telljohann et al., 2009), comunicação entre representantes dos trabalhadores e estruturas de representação (Wills, 2000), ação sindical e reivindicação coletiva (Lecher et al., 1999; Telljohann, 2005) e fomento de uma identidade laboral europeia (Whittall; Knudsen; Huijgen, 2007).

O objetivo que presidiu à Diretiva 94/45/CE foi a melhoria do direito à informação e consulta dos trabalhadores nas empresas ou grupos de empresas de dimensão comunitária (isto é, empresas com 1.000 ou mais trabalhadores nos Estados-Membros e que, em pelo menos dois Estados-Membros diferentes, emprega um mínimo de 150 trabalhadores em cada um deles). Objetivo buscado, por um lado, através da concessão de direitos de informação sobre questões transnacionais capazes de afetar consideravelmente os interesses dos trabalhadores. Por outro, da atribuição de direitos de consulta, vertidos na troca de opiniões e diálogo entre os representantes dos trabalhadores e a direção central ou outro nível de direção mais adequado. Ora, de entre as matérias sobre as quais devem incidir os referidos direitos de informação e consulta, contam-se: a estrutura da empresa; a situação económica e financeira; a evolução provável das atividades, produção e vendas; a situação e evolução provável do emprego; os investimentos; as alterações de fundo relativas à organização; a introdução de novos métodos de trabalho ou de novos processos de produção; as transferências de produção; as fusões, a redução da dimensão ou encerramento de empresas, de estabelecimentos ou de partes importantes de estabelecimentos; os despedimentos coletivos.

Como tem sido reconhecido por académicos e responsáveis de organizações sindicais europeias, os CEEs são exemplo dos maiores avanços da legislação social europeia. Mas, além da sua criação de cima para baixo (Miller, 1999), combinando as vertentes empresarial e setorial, o poten- 
cial dos CEEs desenha-se também de baixo para cima, em nome de uma faceta cosmopolita assente em discursos e práticas de resistência (Santos, 1995) e, portanto, estimulando a articulação de formas de organização laboral em resultado da partilha de problemas comuns entre trabalhadores de diferentes filiais (e países) de uma mesma multinacional. Consequentemente, gerando formas de solidariedade transnacional entre trabalhadores e sindicatos, seja com base em redes horizontais entre trabalhadores europeus (Wills, 2001), seja estimulando a criação de redes verticais entre a "base" e o "topo", isto é, entre trabalhadores e administradores das empresas, combinando, assim, orientação estratégica com mobilização de base (Hyman, 2001).

Nessa conjuntura de potencialidades, foram identificados, em distintos setores e CEEs, boas práticas relacionadas com: a diversificação dos assuntos que foram objeto de informação e consulta (como a responsabilidade social empresarial; a igualdade de género, etc.); o reforço do número de reuniões entre trabalhadores e administrações; a organização de reuniões em que o conflito entre "eles" (capital) e "nós" (trabalho) é relegado para segundo plano, e os representantes dos trabalhadores (de diferentes nacionalidades) e da administração se encontram misturados; a cooperação entre sindicatos na escolha do representante dos trabalhadores para o CEE; a mudança (alternância/descentralização) dos locais de realização das reuniões; o recurso frequente a newsletters electrónicas; o acesso gratuito de todos os representantes em CEEs a telefone, fax, fotocópias, Internet e conta de email; a formação permanente para representantes de trabalhadores em CEEs etc. (Costa; Costa, 2014).

Não obstante esses sinais (mais pontuais do que frequentes) de uma militância efetiva, desde 2011, com a entrada em vigor da Diretiva 2009/38/CE, procurou-se algum upgrade da lei comunitária em aspetos como: o reforço da vertente de "transnacionalidade" da Diretiva; a pre- 
visão de sanções a aplicar, em caso de violação das obrigações presentes na Diretiva; a melhoria de proteção dos representantes dos trabalhadores, através uma melhor aplicação dos seus direitos (de informação e consulta); a possibilidade de dotação aos membros do grupo especial de negociação (responsável por criar as condições para a instituição de um CEE) de ações de formação sem perdas remuneratórias; a convocação dos representantes sindicais enquanto peritos do grupo especial de negociação; uma representação mais equilibrada dos trabalhadores em CEEs segundo as suas atividades, categorias profissionais e o sexo; um reforço das articulações entre níveis de informação e consulta, em especial entre os níveis europeu e local etc. (Costa; Costa, 2014; Laulom; Dorssemont, 2015).

Porém, independentemente dessa revisão - que, ainda assim, ficou um pouco aquém, quer quanto ao número adicional de CEEs criados, quer quanto à sua qualidade (De Spiegelaere, 2015) - e do facto de os CEEs já antes terem servido de referência para outras experiências fora do espaço europeu - como foi o caso do contrato coletivo do MERCOSUL da Volkswagen (Costa, 2008) -, não deixaram de persistir vários obstáculos. Por um lado, relacionados com o funcionamento dos CEEs em termos genéricos, os quais se traduziram: na identificação de diferenças significativas na capacidade formal dos representantes dos trabalhadores de exercerem o seu papel; na observação de processos pouco claros de seleção de representantes de trabalhadores (não raras vezes indicados pelas administrações das empresas); na consagração dos CEEs mais como prolongamento de diferentes estruturas nacionais de informação e consulta dos trabalhadores do que como genuínas instituições europeias, etc..

Por outro, no caso português, importa salientar que as principais centrais sindicais - a Confederação Geral dos Trabalhadores Portugueses (CGTP) e União Geral de Trabalhadores (UGT) - reconhecem que os CEEs podem reforçar direitos laborais à escala da empresa transnacional. 
Porém, há diferenças de perceção entre elas. Por um lado, a CGTP (de orientação comunista e antieuropeísta) sempre considerou que os CEEs não evitariam a arbitrariedade associada aos processos de restruturação empresarial. Nesse sentido, nunca considerou que os CEEs fossem a grande conquista do movimento sindical europeu. Por outro lado, a UGT (de orientação socialista/socialdemocrata e pró-integração europeia) tende a valorizar os CEEs e o seu potencial negocial, com base nas orientações emanadas das confederações sindicais internacionais nas quais se integrou, desde que foi constituída no final dos anos 1970s (Costa, 2013). Pode dizer-se que a lógica competitiva entre estruturas sindicais é um traço típico do Sul da Europa (em especial do caso português) e reproduz-se na arena transnacional ou nas visões que, a esse respeito, se constroem sobre os CEEs. Ora, esse posicionamento distinto antecipa alguns obstáculos mais diretamente relacionados com o modus operandi dos CEEs, a saber: as interferências das administrações das empresas na escolha dos representantes para os CEEs; a competição entre estruturas sindicais (sobretudo quando está em causa a possibilidade de ocupar um lugar ímpar de representação); a atribuição de um sentido utilitarista aos CEEs (pois muitos trabalhadores entendem que os CEEs podem ser um órgão de obtenção de melhores condições salariais); a fraca cultura de participação ao nível da empresa, etc.

Além disso, foram identificados obstáculos à constituição de CEEs em multinacionais com sede em Portugal, tais como: i) as prioridades definidas pelos representantes de trabalhadores tendem a secundarizar o papel dos CEEs, pois remetem para preocupações essencialmente nacionais, essas sim consideradas prioritárias; ii) o direito à informação e consulta é considerado como já existente na legislação relativa às comissões de trabalhadores, o que retarda também o foco nos CEEs; iii) os processos de privatização empresarial são geradores de relações laborais mais 
instáveis e, nessa medida, uma possível entrada de novos trabalhadores com condições contratuais menos favoráveis não constitui um estímulo à participação laboral (através dos CEEs); iv) a constituição de CEEs afigura-se um processo moroso, que implica quer negociações com a entidade empregadora (que são muitas vezes tensas), quer a definição de estratégias de aproximação entre trabalhadores, em especial quando estes são provenientes de culturas sindicais distintas; v) o facto de muitos representantes nem sempre exercerem essa condição a tempo inteiro torna-os menos disponíveis para uma acumulação de funções de representantes em CEEs e de representantes em organizações nacionais; vi) o reduzido número de ações de formação sobre a problemática dos CEEs, quer promovido pelas administrações das multinacionais, quer pelas organizações representativas dos trabalhadores; vii) a (quase) inexistência de experiências nacionais em CEEs, que pudessem constituir uma referência a ter em conta; vii) consequentemente, nem sempre se atribui aos CEEs um sentido de eficácia capaz de desbloquear as tensões entre capital e trabalho à escala da empresa multinacional (Costa; Araújo, 2009, pp. 45-52; Costa; Costa, 2014, pp. 126-127).

\section{A dimensão formal dos CEEs}

A pesquisa anterior por mim coordenada (Costa; Costa, 2014) esteve centrada em vários setores (metalúrgico, químico e financeiro) e na análise do conteúdo de 111 acordos de CEEs em que existiam representantes portugueses (quadro 1). Na verdade, o processo de institucionalização dos CEEs passa pela celebração de acordos formais entre administrações e trabalhadores. São esses acordos que estabelecem, por assim dizer, as condições de transnacionalidade legal que servem de base à transnacionalização da militância sindical/laboral. 
Quadro 1. Multinacionais, por presença em Portugal, setores, CEE e existência de representante português

\begin{tabular}{|l|c|c|c|c|}
\hline \multicolumn{1}{|c}{} & Químico & \multicolumn{1}{c|}{ Metalúrgico } & \multicolumn{1}{c|}{ Financeiro } & Total \\
\hline Multinacionais & 452 & 816 & 141 & 1409 \\
\hline $\begin{array}{l}\text { Multinacionais } \\
\text { em Portugal }\end{array}$ & 122 & 200 & 38 & 360 \\
\hline Com CEE & 83 & 130 & 24 & 237 \\
\hline $\begin{array}{l}\text { Acordos com repre- } \\
\text { sentante Português }\end{array}$ & 39 & 57 & 15 & 111 \\
\hline
\end{tabular}

Fonte: Costa e Costa (2014, p. 130)

Da análise de conteúdo dos acordos, destaco aqui apenas 5 tópi$\cos ^{2}$ a as questões objeto de informação e consulta; a referência à oportunidade da informação e consulta; as questões expressamente excluídas da agenda; a confidencialidade; e a formação de representantes. Como se verá, alguns desses tópicos confirmam as dificuldades relacionadas com a "conceção" dos CEEs subjacente aos acordos.

\section{i) Questões objeto de informação e consulta}

Nos 111 acordos analisados, as questões mais recorrentes foram as seguintes: situação económica e financeira da multinacional; estrutura e organização; análise prospetiva; principais alterações organizacionais e estruturais previstas; principais tendências ao nível do emprego; projetos, investimentos e estratégias da multinacional; novos métodos de trabalho, de produção e às novas tecnologias; transferências, deslocalizações, fu-

\footnotetext{
2 Note-se, no entanto, que a pesquisa foi mais abrangente, pois o estudo dos acordos implicou uma análise pormenorizada da sua natureza, que contemplou: o tipo de acordo, os subscritores, a legislação aplicável, a duração do acordo, a composição do CEE, o carácter abrangente versus carácter restrito dos acordos, a oportunidade da informação e da consulta, as formas de eleição dos representantes, os modos de funcionamento das reuniões etc. (Costa; Costa, 2014).
} 
sões, aquisições, reduções de pessoal, despedimentos coletivos e encerramentos; produção e vendas (produtividade e competitividade). Por outro lado, questões como as condições de trabalho (remunerações, horários de trabalho, etc.), a formação profissional, a saúde, higiene e segurança no trabalho, o ambiente, a igualdade de oportunidades, a legislação europeia, e a representação sindical só muito esporadicamente constam dos acordos.

Partindo deste leque de questões, distinguiu-se entre acordos restritos (circunscritos à letra da Diretiva) e acordos mais abrangentes (que vão para além do estabelecido na Diretiva).

Quadro 2. Tipologia das questões objeto de informação e consulta

\begin{tabular}{|c|c|c|}
\hline \multirow{9}{*}{$\begin{array}{l}\text { Acordos } \\
\text { restritos }\end{array}$} & 1 & Situação económica e financeira \\
\hline & 2 & Estrutura e organização \\
\hline & 3 & Análise prospetiva \\
\hline & 4 & Alterações organizacionais e estruturais \\
\hline & 5 & Principais tendências ao nível do emprego \\
\hline & 6 & Projetos, investimentos e estratégias \\
\hline & 7 & Novos métodos de trabalho e produção/ novas tecnologias \\
\hline & 8 & $\begin{array}{l}\text { Transferências, deslocalizações, fusões, aquisições, cisões, } \\
\text { reduções de pessoal, despedimentos coletivos, encerramentos }\end{array}$ \\
\hline & 9 & Produção e vendas \\
\hline \multirow{7}{*}{$\begin{array}{l}\text { Acordos } \\
\text { abrangentes }\end{array}$} & 10 & $\begin{array}{l}\text { Condições de trabalho (vínculos contratuais, remunerações, } \\
\text { horários laborais, etc.) }\end{array}$ \\
\hline & 11 & Formação profissional \\
\hline & 12 & Segurança, higiene e saúde \\
\hline & 13 & Ambiente \\
\hline & 14 & Igualdade de oportunidades \\
\hline & 15 & Legislação europeia \\
\hline & 16 & Representação sindical \\
\hline
\end{tabular}

Fonte: Costa e Costa (2014, p. 150) 
Apesar de quase não haver disparidade entre um e outro tipo de acordos, 56 acordos foram classificados como restritos. A ausência de outras questões nas agendas dos CEEs revela a incapacidade dos representantes dos trabalhadores para, no processo de negociação dos acordos, irem além dos requisitos da Diretiva. Por outro lado, no caso dos 51 acordos que foram classificados como abrangentes, essa abrangência limitou-se a duas questões (25 acordos ou 49\%), podendo também chegar às 3 questões em $22 \%$ dos casos (11 acordos). As questões mais recorrentes dizem respeito à segurança, higiene e saúde no trabalho, ao ambiente e à formação profissional. Questões como as condições de trabalho (salários, principalmente) e a igualdade de oportunidades são ainda uma raridade no leque das questões a serem debatidas em sede dos CEEs.

ii) Oportunidade da informação e consulta

$\mathrm{Na}$ linha de estudos anteriores realizados no contexto europeu, é reduzido o número dos acordos que fazem referência explícita ao facto de a informação e consulta deverem ter lugar em tempo útil, ou seja, previamente à tomada de qualquer decisão suscetível de afetar os interesses dos trabalhadores. Tal sucede apenas em 38 dos 111 acordos estudados (34,2\%). De resto, nalguns acordos está explicitamente estabelecido que a direção central e/ou respetivas sucursais são os únicos órgãos competentes para sugerir/implementar decisões.

iii) Questões expressamente excluídas dos acordos

Quase metade dos acordos analisados (56) faz referência explícita a questões que não podem ser objeto de informação e consulta em sede dos CEEs. As matérias mais recorrentes dizem respeito: aos problemas relacionados com unidades nacionais isoladamente e às questões potencialmente prejudiciais para a multinacional. 
Quadro 3. Questões expressamente excluídas

\begin{tabular}{|l|c|c|}
\hline & $\mathrm{N}$ & $\%$ \\
\hline Relacionadas com unidades nacionais & 24 & $21,6 \%$ \\
\hline Potencialmente prejudiciais para a multinacional & 10 & $9,0 \%$ \\
\hline Relacionadas com unidades nacionais + Potencialmente prejudiciais & 8 & $7,2 \%$ \\
\hline $\begin{array}{l}\text { Relacionadas com unidades nacionais + Potencialmente prejudiciais } \\
+ \text { Remunerações, compensações, benefícios e condições } \\
\text { de trabalho }\end{array}$ & 4 & $3,6 \%$ \\
\hline $\begin{array}{l}\text { Relacionadas com unidades nacionais + Remunerações, } \\
\text { compensações, benefícios e condições de trabalho }\end{array}$ & 2 & $1,8 \%$ \\
\hline $\begin{array}{l}\text { Relacionadas com unidades nacionais + Negociação } \\
\text { coletiva }\end{array}$ & 1 & $0,9 \%$ \\
\hline Outras situações* & 7 & $6,3 \%$ \\
\hline Não referido & 111 & $100,0 \%$ \\
\hline Total & 55 & $49,5 \%$ \\
\hline
\end{tabular}

Fonte: Costa e Costa (2014, p. 155)

* Incluem combinações variáveis de questões expressamente excluídas (nacionais, potencialmente prejudiciais, negociação coletiva e condições de trabalho).

Igualmente, na linha da argumentação de Costa e Araújo (2009, p. 84), sendo o objetivo da Diretiva melhorar o direito dos trabalhadores à informação e consulta transnacionais, é compreensível que sejam mais frequentemente excluídas das agendas e competências dos CEEs as questões respeitantes às unidades nacionais (24 acordos ou 21,6\%). Porém, apesar dessa reserva, alguns acordos salvaguardam a possibilidade de, em circunstâncias excecionais (reestruturações, deslocalizações, encerramentos, despedimentos coletivos, etc.), realizarem-se encontros entre os 
representantes dos trabalhadores da unidade afetada, os representantes dos trabalhadores do CEE e a direção central. A própria Diretiva prevê, de resto, a realização de reuniões extraordinárias para esse efeito.

\section{iv) Confidencialidade}

Nos termos do artigo $8^{\circ}$ da Diretiva dos CEEs em vigor, designadamente no ponto 1 ,

os Estados-membros devem dispor que os membros do grupo especial de negociação e do conselho de empresa europeu, bem como os peritos que eventualmente os assistam, não são autorizados a revelar a terceiros as informações que Ihes tenham sido expressamente comunicadas a título confidencial. O mesmo se aplica aos representantes dos trabaIhadores no âmbito de um procedimento de informação e consulta. Esta obrigação mantém-se seja qual for o local em que os representantes se encontrem, mesmo após o termo dos respetivos mandatos.

Ora, o que a análise dos acordos evidencia é que a questão da confidencialidade se encontra explicitamente prevista em 97 dos 111 acordos, ou seja, em 87,4 \% dos acordos. Trata-se de uma maioria esmagadora, bem reveladora das cautelas das multinacionais quanto à proteção dos seus interesses, por vezes, mesmo quando os assuntos não o justificariam.

\section{v) Formação dos representantes}

Nos acordos analisados, sobressaíram três linhas de força. Em primeiro lugar, um elevado número de acordos que simplesmente não menciona a formação dos representantes (49 acordos ou 44,1\%). Em segundo lugar, a formação em Línguas aparece isoladamente em 20 acordos (18\%). Em terceiro lugar, a referência à formação de uma forma ambígua: aquela que é necessária para que os representantes desempenhem adequadamente as suas funções no âmbito dos CEEs (18 acordos ou 16,2\%). 
Em resumo, os cinco tópicos aqui analisados evidenciam a persistência de "pedras formais" no percurso dos CEEs. Daí que o processo de revisão da Diretiva (a que acima fiz referência) tivesse em mente corrigir alguns desvios no sentido de melhorar a lei comunitária. Mas a dimensão formal, sendo central, não explica tudo. No dia a dia do funcionamento dos CEEs, podem existir situações que vão além dos conteúdos dos acordos. O CEE do grupo VW é um desses casos em que se criou espaço para boas práticas laborais.

\section{As boas práticas como guia de militância transnacional: o CEE do Grupo VW}

Em paralelo com a análise formal dos CEEs, na mesma pesquisa (Costa; Costa, 2014) realizaram-se entrevistas em profundidade a representantes portugueses membros de CEEs e de "comités restritos"3, pois, tratando-se de trabalhadores com uma maior intensidade de interações com a sede da empresa, poderiam também dar conta de experiências de boas práticas. O setor metalúrgico aparece aqui em destaque, pelo facto de ser o setor com mais multinacionais presentes em Portugal e com mais CEEs constituídos ${ }^{4}$ Por outro lado, o facto de a filial portuguesa do grupo Volkswagen (VW) (a fábrica da Autoeuropa) constituir um exemplo de referência à escala do país - por sinal responsável por 1,1\% do PIB portu-

\footnotetext{
3 Nos termos dos considerandos 33 e 44 da Diretiva em vigor, bem como do seu anexo I, 1.d), o "comité restrito" encontra-se previsto na celebração dos acordos de CEEs, podendo ser composto de até 5 membros. Tal comité visa garantir uma melhor coordenação e uma maior eficácia da atividade regular do CEE, assim como uma informação e consulta rápidas em casos excecionais.

4 Trata-se, aliás, desde o início da constituição de CEEs, do setor mais representativo (De Spiegelaere; Jagodzinski, 2015) como também se constata na base de dados online do Instituto Sindical Europeu, disponível em http://www.ewcdb.eu/stats-and-graphs (consultada em 27.03.2017).
} 
guês (Expresso, 4.10.2015)5 - faz com que mereça uma atenção especial. Assim, na linha de entrevistas anteriores por mim realizadas (em 2006 e em 2010) ao representante português do CEE do grupo VW, foi novamente realizada (em 22.04.2016) uma extensa entrevista a esse representante, por sinal com grande experiência quer na comissão de trabalhadores, quer no plano sindical, quer no CEE e no comité restrito do CEE.

Se tivermos em mente os dados sobre os cinco tópicos de análise dos acordos trabalhados na seção anterior, constataremos que, a priori, o caso da VW não esteve tão condicionado por tais constrangimentos formais. Desde logo, porque: as matérias objeto de informação e consulta se revelaram mais diversificadas e abrangentes; a informação e consulta tende a ocorrer em tempo útil; os problemas nacionais relacionados com cada fábrica do grupo não são secundarizados; o recurso à confidencialidade é utilizado de modo prudente pela administração; a formação de representantes, embora não conste do acordo de criação do CEE da VW, na prática existe, como se testemunha na fábrica portuguesa (Costa; Costa, 2014). Mesmo havendo condições formais que, quando comparáveis com o panorama geral de CEEs, se afiguram mais vantajosas, as boas práticas ganharam vida para além desse registo formal. Daí que seguidamente se destaquem: a cultura de parceria social; a interlocução especial com a comissão de trabalhadores; a efetividade da democracia laboral; e a demonstração de práticas avançadas.

\subsection{Uma cultura de parceria social}

Este ponto assinala a importância histórica do papel da negociação induzido pela tradição da "casa mãe" da empresa, i.e., por uma "cultura alemã" orientada para evitar o encerramento de empresas (Costa, 2013).

\footnotetext{
${ }^{5}$ Ver igualmente, no mesmo sentido, o site oficial da fábrica portuguesa: https://www.volkswagenautoeuropa.pt/empresa/factos-numeros(consultado em 15.06.2017).
} 
Na verdade, o Grupo VW pôs em prática, ao longo de décadas, uma cultura de proteção dos trabalhadores já existente antes mesmo da criação do CEE (em 1992). Com o surgimento do CEE, nesta data e por iniciativa do sindicato alemão IG-Metall (Industriegewerkschaft Metall), esse espírito de diálogo seria reforçado, pois não só a administração da VW viu no CEE um instrumento útil para envolver os representantes dos trabalhadores nas políticas do Grupo, como os representantes dos trabalhadores associaram o CEE a mais coesão interna e a um reforço da influência transnacional do Grupo (Costa; Costa, 2014).

Aliás, como sempre salientou o representante dos trabalhadores do CEE do Grupo VW nos diversos momentos em que foi entrevistado (2006, 2010, 2016), desde que o CEE foi criado, nenhuma fábrica encerrou. Para tal, em muito contribui a designada "lei-VW", criada em 1960, e que confere direitos de cogestão ao conselho de supervisão (fiscalização). Assim, para encerrar uma fábrica, são precisos $80 \%$ dos votos, mas como o conselho de supervisão é composto por 20 elementos (10 representantes de trabalhadores e 10 acionistas) esse processo fica dificultado (Speidel, 2012).

Quando questionado sobre o que terá sido mais decisivo para o não encerramento de fábricas da VW - se a "lei-VW" ou o CEE em si mesmo -, o representante português no CEE enfatizou que uma coisa condiciona a outra: "a existência da chamada Lei VW é que permite que o CEE tenha o poder de influência que tem. Não é por acaso que todos os representantes dos trabalhadores alemães que fazem parte do conselho de supervisão fazem também parte do CEE e do comité mundial" (entrevista, 22.04.2016). Aliás, como prova da eficácia do CEE, este representante referiu-se ao modo como a crise de emprego ocorrida em 2011 (por sinal, num contexto de agravamento da crise económica em Portugal, numa altura em que o país já estava sob assistência financeira internacional da troïka, isto é, do Banco Central Europeu, da Comissão Europeia e do 
Fundo Monetário Internacional) foi solucionada através da intervenção do CEE:

A nossa última crise de emprego aqui foi em 2011, quando fomos confrontados com o facto de termos cerca de 400 pessoas a mais. Além disso, sabíamos que 600 trabalhadores estavam a contrato e corriam o risco de virem para a rua. O que conseguimos, claramente com o apoio do CEE, foi arranjar duzentos e muitos lugares na Alemanha, em Wolfsburgo, mais alguns na Audi [...] As pessoas foram voluntariamente e depois lá passaram a efetivos[...]. Esta questão foi discutida entre mim e o presidente do CEE, e entre o diretor dos recursos humanos daqui e o diretor dos recursos humanos de Wolfsburgo. Primeiro houve reuniões separadas, depois houve reuniões em conjunto (representante português do CEE do grupo VW, entrevista, 22.04.2016).

\subsection{A interlocução preferencial com a comissão de trabalhadores}

Instalada em Portugal em 1991, primeiro como joint-venture composta pelos Grupos Ford e VW, e a partir de 1999 apenas pelo Grupo VW, a fábrica portuguesa da VW (Autoeuropa) tem vindo a evidenciar desempenhos económicos muito favoráveis - e, por sinal, mutuamente reconhecidos pela administração e trabalhadores -, facto que contribuiu também, de forma decisiva, para valorizar o papel do CEE. Na Autoeuropa, são produzidos os modelos Sharan, Scirocco e Alhambra e, em 31.12.2016, a composição da força de trabalho era de 3.295 trabalhadores (segundo dados do site oficial ${ }^{6}$ consultados em 27.03.2017). A articulação da administração com os trabalhadores é feita preferencialmente com a comissão de trabalhadores (CT), em detrimento da representação sindical. Contrariamente ao que sucedia em 2006, quando, num universo de 2.900 trabalhadores, 1.400 eram sindicalizados e a taxa de sindicali-

${ }_{6}$ Disponíveis em: http://www.volkswagenag.com/content/vwcorp/content/en/the_group/production_plants.html 
zação rondava os 45\%, em 2016, mesmo existindo mais trabalhadores, apenas cerca de 17\% (530 trabalhadores) são sindicalizados ${ }^{7}$.

Assumindo uma atitude propositiva, a CT desenvolveu junto da administração e por meio do CEE a opção pela flexibilidade laboral, um pouco na linha do acordo dos down-days celebrado no final de 2003 $\left(\right.$ Costa, 2004) ${ }^{8}$. O que distingue a atuação da CT da atuação dos sindicatos da empresa, em Portugal, é o facto de a primeira estar sintonizada com a cultura de diálogo da casa-mãe (e que, por sinal, é própria dos sindicatos alemães e do funcionamento do CEE), ao passo que os sindicatos assumem uma atitude mais competitiva e ideologicamente orientada. Ainda que os sindicatos reclamem para si o monopólio da contratação coletiva e da negociação de salários, é a CT que tem liderado as negociações salariais com a administração da Autoeuropa.

Em simultâneo com a facilidade de contactos entre capital e trabaIho na empresa portuguesa, a própria CT faz o trajeto "ascendente", isto é, dirige-se à sede, ao vértice estratégico (que é a administração da VW), sempre que considera necessário, ou seja, sempre que alguma questão não fica totalmente resolvida no shopfloor. Não causa, pois, estranheza que seja a coordenação da CT a indicar (nomear) o representante dos trabalhadores no CEE.

\footnotetext{
Esta quebra significativa do número de sindicalizados deve-se ao facto de muitos trabalhadores serem jovens e, com a crise que se adensou em Portugal em 2011, preferiram poupar $1 \%$ da cota que descontavam para o sindicato. Além disso, na fábrica da Autoeuropa, foi implantado um fundo de pensões, desde 2011, para o qual cada trabalhador pode, se assim o entender, contribuir com $2 \%$ e a empresa com outros $2 \%$. Muitos preferem, pois, descontar para o fundo de pensões, em vez de o fazerem para o sindicato.

8 Para fazer face à quebra da produção de veículos resultante da crise mundial do mercado automóvel, a CT e a administração da empresa acordaram que os trabalhadores efetuariam 22 dias de paragem por ano. Este acordo permanece em vigor, apesar de os sindicatos se terem oposto a ele em 2003.
} 


\subsection{Um CEE sintonizado com a democracia laboral}

O CEE do Grupo VW torna possível a democracia laboral. Isso é notório na preocupação do CEE para com os eventuais problemas de cada filial. Ou seja, ao contrário do que é a prática em muitos CEEs (refletindo os conteúdos dos acordos), não é preciso que um problema ocorra em pelo menos dois Estados do Espaço Económico Europeu para que ele possa ser resolvido, o que significa que o CEE permite que se trate primeiro dos problemas mais graves e só depois dos problemas comuns a várias filiais do Grupo VW. Ainda assim, mesmo sendo escassos, foram os seguintes os principais problemas da fábrica portuguesa que nos últimos anos foram levados ao CEE: o encerramento do posto médico ao fim de semana; a destituição de um team líder por ser membro da CT; a não automatização das cabines de pintura; o conhecimento dos destinos dos investimentos futuros da empresa; a substituição de um administrador que prejudicava as relações com os trabalhadores. Todos estes problemas foram resolvidos e o papel do CEE, enquanto mecanismo de pressão transnacional para a solução de problemas locais, foi decisivo.

Um outro sinal revelador da democracia propiciada pelo CEE prende-se ao facto de a informação e a consulta aos trabalhadores se considerarem suficientes e atempadas. O formato das reuniões do CEE do Grupo VW e a sua preparação prévia são, na verdade, aspetos que concorrem para um esclarecimento ponderado e atempado dos problemas que possam surgir e, consequentemente, para um bom funcionamento do CEE. Não obstante a organização das reuniões do CEE permitir um conhecimento atempado das questões a discutir, uma vez que os relatórios são previamente enviados por e-mail em três línguas distintas (inglês, alemão e língua do representante) a todos os representantes, o facto é que a agenda dos problemas é flexível. Ou seja, não há propriamente uma agenda prévia, fixa ou imposta pela administração, pois isso é definido em reu- 
nião entre as próprias organizações representativas de trabalhadores (CT, sindicatos ou outras).

Por norma, o formato das reuniões do CEE do Grupo VW cria condições de aproximação entre representantes de trabalhadores, numa base que começa por ser essencialmente informal e que, depois, se torna mais formal à medida que vai deixando de ser "entre iguais". Com efeito, as reuniões do CEE ocupam sempre mais do que um dia. O primeiro dia é para os representantes dos trabalhadores discutirem entre si o tipo de problemas que têm, o que sucede sem a presença de elementos da administração do grupo. O segundo dia está normalmente reservado ao encontro entre trabalhadores e diretores de recursos humanos. O terceiro dia fica então reservado para a reunião entre representantes de trabalhadores e a administração do Grupo VW. ${ }^{9}$

A importância dos contactos informais e a noção de solidariedade entendida como sinónimo de reciprocidade são mais dois sinais do bom funcionamento do CEE do Grupo VW. Por um lado, os contactos informais são importantes por permitirem, por vezes, o acesso a informações que nem sempre são veiculadas no espaço formal da reunião, ou mesmo abrirem caminho para a resolução de problemas. Além disso, é igualmente curioso registar que, inclusive no quadro das reuniões do CEE, se podem partilhar informações relativas ao universo automobilístico e não apenas à VW, como sucedeu, por exemplo, como a informação transmitida via CEE do Grupo VW de que a empresa Opel-General Motors, em Portugal, iria ser encerrada (como acabaria por suceder em novembro de

\footnotetext{
9 Entretanto, como estratégia de otimização de recursos em face dos mais de 600.000 trabalhadores e do número de marcas (12) do Grupo VW, têm-se vindo a implementar uma reorganização das reuniões: antes tínhamos duas reuniões, uma de dois dias e outra de três. Agora temos uma de cinco. Engloba o CEE e o comité mundial [...]. Fazemos na mesma as reuniões, mas em dias seguidos: primeiro com os representantes da Europa e depois com os restantes elementos do mundo inteiro (representante português do CEE do grupo VW, entrevista, 22.04.2016).
} 
2006). Este exemplo é revelador de que os CEEs estão longe de ser informados atempadamente, pois ao mesmo tempo que (com antecedência) uma informação era veiculada no CEE do Grupo VW essa mesma informação não era comunicada no CEE da própria General Motors Europa (Costa; Araújo, 2009).

Por sua vez, a questão da solidariedade é central no funcionamento de qualquer CEE. Trata-se, no caso do CEE do Grupo VW, de uma solidariedade internacional, e não apenas europeia, direcionada para evitar o encerramento de fábricas. Nesse sentido, conta com o apoio do já referido conselho de supervisão da VW e do peso que nele têm os representantes dos trabalhadores. A solidariedade implica, pois, ações concertadas e um abdicar de posições sectaristas. Como se disse acima, as reuniões entre representantes de trabalhadores criam uma cultura de aproximação entre eles e não de distanciamento, mesmo tendo em conta que existe uma predisposição para que cada representante de cada país esteja, sobretudo, interessado nas mutações que venham a afetar a força de trabalho na sua fábrica, e mesmo sabendo que há "disputa" entre as fábricas para que a produção de mais um veículo seja feita em sua "casa". Daí que, na ótica dos representantes de trabalhadores nacionais, seja importante não só mostrar capacidade de trabalho junto das administrações (locais e centrais), mas igualmente acionar estratégias de persuasão junto dos representantes de trabalhadores da sede da VW, pois cabe a eles um papel decisivo e direito de voto no referido conselho de supervisão da VW, que decide sobre as orientações/destinos da própria produção. Além disso, o capital simbólico (relacional) entre trabalhadores (designadamente entre representantes de trabalhadores mais experientes, como é o caso do representante português do CEE do Grupo VW) pode também fazer a diferença. 


\subsection{Um CEE de práticas avançadas}

A(s) prática(s) avançada(s) do CEE do Grupo VW reside(m) na maximização de outros mecanismos de diálogo social transnacional. Um deles foi, logo em 2002, a Carta Social da VW (assinada em Bratislava em 06.06.2002). Tratou-se de um novo marco das relações laborais para o universo da VW, não só por caminhar para uma harmonização transnacional das relações laborais, como por colocar ênfase nas formas de responsabilidade social das empresas (Steiert; Uhl; Brüning, 2002). O referido documento - intitulado Declaração sobre direitos sociais e relações industriais na Volkswagen - foi subscrito pela administração central da VW na Alemanha, pela Comissão de Trabalhadores do Grupo Mundial VW e pela Federação Internacional dos Trabalhadores das Indústrias Metalúrgicas (FITIM), tendo-se baseado nas principais convenções da OIT.

Outro dos mecanismos de diálogo e participação laboral criado na sequência daquela Carta Social de 2002 foi a Carta das relações laborais no Grupo Volkswagen, celebrada entre a administração mundial da VW, as CTs europeias e mundial e a FITIM, em 29.10.2009. Trata-se de uma carta em que se confirma a tradição de cultura de participação de que se falava acima e que tem enquadrado a atividade do CEE do Grupo VW. Esta Carta vem aplicar-se a todas as empresas e unidades industriais representadas na CT europeia e na CT mundial do Grupo Volkswagen e vem definir os direitos de participação na empresa. As partes reconhecem as várias tradições sindicais, distintas de país para país, existentes no seio do Grupo VW, assumindo conjuntamente o objetivo de desenvolvimento das relações laborais coletivas a nível local. A Carta (assinada pela administração e pela CT da Autoeuropa em 15.11.2010) estabeleceu um quadro vinculativo para a continuação do desenvolvimento responsável das relações laborais existentes, no sentido da cooperação na resolução de conflitos. 
Além dos direitos de participação das associações de trabalhadores em assuntos financeiros, em assuntos de política de recursos humanos e sociais da empresa, da definição de regras relativas à celebração de um "acordo de participação específico de unidade de âmbito local" e da definição de regras gerais de procedimento após a celebração do acordo, merece destaque a clarificação que é feita em matéria de direitos de participação, designadamente de informação, consulta e cogestão(VW AG; CT Europeia do Grupo VW; CT Mundial do Grupo VW; FITIM, 2009).

O papel do CEE foi importante na fase da conceção desta Carta das relações laborais no Grupo Volkswagen, pois o CEE e o conselho de empresa mundial, juntamente com a administração do Grupo VW, rubricaram a primeira versão em alemão do documento. Na sequência disso, o documento "desceu" às fábricas de modo a ser adaptado a cada realidade. Na verdade, ao comentar a sua importância, o representante português dos trabalhadores no CEE do Grupo VW realçou o direito à cogestão, bem como o papel "descentralizador" do CEE nesse domínio.

A Carta das Relações Laborais é uma mais-valia e a missão do CEE foi fazer aquilo. Primeiro houve negociação a partir de cima e depois isso foi complementado pela legitimidade da pressão a partir de baixo, da ação das organizações de trabalhadores, em especial da CT, no caso da Autoeuropa (entrevista, 22.04.2016).

O valor acrescentado desta carta reside, pois, na possibilidade da CT monitorizar assuntos como promoções, aumentos de salários, admissões, refeitórios, etc.:

Algumas coisas que em Portugal são meramente informativas ou consultivas nesta Carta são imperativas. Por exemplo, em Portugal nenhuma legislação obriga que a empresa tenha que me ouvir, reunir comigo ou decidir comigo questões de carácter social, como por exemplo, saber como é que o refeitório é feito, quantas mesas deve ter por pessoa, 
Sociologias, Porto Alegre, ano 19, no 45, mai/ago 2017, p. 82-112

etc. Outros exemplos são as questões dos seguros de saúde ou as admissões de pessoal que têm que ser discutidas connosco, os concursos internos têm de ter a nossa consulta e concordância prévias (representante português do CEE do grupo VW, entrevista, 22.04.2016).

Em síntese, a tradição de cultura negocial da VW, a "lei-VW" que a sustenta e a reforça, o não encerramento de fábricas, a preocupação com os problemas das filiais consideradas isoladamente e o empenho coletivo na tentativa de resolução de problemas (primeiro nacionalmente e depois, caso no local não haja entendimento, via CEE), a concretização de uma prática do CEE que vai além dos termos formais do acordo que Ihe dá vida (realização de reuniões sempre que necessário; mais solidariedade; dinamização de focos de diálogo social transnacional em resultado da existência do CEE ou instigados pela ação deste; maior conhecimento sobre a empresa e também sobre o setor etc.) são apenas alguns dos fatores que tornam plausível classificar este CEE como "CEE participativo" ou "eurocêntrico", nos termos das tipologias propostas por Lecheret al.(1999) e por Bicknell (2007), respetivamente. Como assinalavam Da Costa e Rehfeldt (2006, p. 99), no CEE da VW o "direito de informação e de consulta prévios vão muito longe e bem para além da maior parte dos acordos de constituição de CEEs".

\section{Conclusão: rumo a uma coesa identidade laboral transnacional?}

Apesar das mais de duas décadas de existência formal, os CEEs evidenciam ainda um processo de construção progressiva e de envolvimento em dinâmicas transnacionais (Waddington, 2011). O que significa um potencial assinalável por explorar. Como consideram Telljohann et al. (2009), "a europeização das relações laborais, e particularmente a adoção da Diretiva sobre conselhos de empresa europeus, desempenhou um pa- 
pel maior no caminho que conduziu à negociação coletiva transnacional e aos acordos-quadro globais". Nesse sentido, e até pela relevância que detêm no quadro do sindicalismo europeu (Bernaciak; Gumbrell-McCormick; Hyman, 2014), os CEEs continuam a anunciar várias potencialidades: conferir aos representantes de trabalhadores maiores possibilidades de interlocução e afirmação perante as administrações locais; permitir às administrações centrais a aquisição de um maior conhecimento da amplitude dos problemas dos trabalhadores das diferentes filiais; propiciar uma melhor comparação entre filiais, de modo a percecionar melhor as distinções bem como as reivindicações; aceder a um patamar de decisão superior, exercendo formas de pressão complementares aos mecanismos nacionais; reforçar uma cultura de diálogo social na empresa, etc. (Costa; Costa, 2014).A todas essas potencialidades, deve adicionar-se uma outra, de resto já referida quando me reportei ao caso da VW (Autoeuropa): a ideia de solidariedade. Sempre que esta for assumida como genuína - isto é, como garante de reciprocidade, complementaridade ou afinidade uma transnacionalização laboral estará mais perto de ocorrer.

Mas a vigilância permanente é necessária. No caso do Grupo VW, observou-se que uma conjuntura económica favorável se constituiu como "regra de ouro" que ajudou a conferir eficácia aos CEEs e a encontrar soluções de rotação de trabalhadores sempre que a ameaça de despedimento pairava no ar. Todavia, tal conjuntura estará sempre a ser posta à prova e a exigir intervenção e monitorização permanentes, quer localmente, quer à escala global em que o Grupo VW atua. Localmente, porque, não obstante os anúncios de investimento divulgados pela fábrica portuguesa nos últimos anos ${ }^{10}$, os problemas de excesso de mão de obra vão certamente

\footnotetext{
10 Em abril de 2016, a Autoeuropa anunciou um investimento de 670 milhões de euros até 2019, a criação de 500 novos empregos e a produção de um novo modelo da marca. Por sua vez, em outubro de 2016 era anunciado o recrutamento de 1500 trabalhadores para a produção de um novo modelo a partir de meados de 2017.
} 
continuar na ordem do dia ${ }^{11}$. E, claro, globalmente (certamente de modo ainda mais decisivo, pois é da situação financeira do Grupo que emergem possíveis repercussões para várias filiais da VW), as incertezas vão sempre pairar no ar durante muito tempo, sobretudo em resultado do conhecido escândalo da manipulação dos resultados dos testes de emissões de gases poluentes que atingiu o Grupo VW e que foi tornado público em outubro de 2015. Na verdade, estão ainda por medir os verdadeiros impactos deste escândalo, sobretudo atendendo ao facto de existirem cerca de 10.000 trabalhadores temporários no Grupo VW em toda a Europa. É claro que, no caso do escândalo, não pode ser imputada qualquer culpa aos trabaIhadores. Igualmente, não seria admissível que o assunto da manipulação dos kits fosse sequer objeto de informação em sede do CEE da VW.

Em resumo, uma vez que comportamentos das multinacionais são imprevisíveis e nem sempre a fronteira entre as boas práticas e as más práticas é clara, o papel dos CEEs e das demais organizações representativas de trabalhadores nas filiais das multinacionais terá inevitavelmente que ser de vigilância e exigência permanentes. Só desse modo também se contribuirá para reforçar a identidade laboral europeia que subjaz aos CEEs e, nessa linha, para abrir um espaço de revitalização da militância sindical/laboral transnacional.

\footnotetext{
11 Na linha do que sucedera em 2011, em meados de 2016, a Autoeuropa viu-se confrontada com a necessidade de colocar 300 trabalhadores fora do país, mais precisamente em Osnabruck. Nesse processo, o papel do CEEfoidecisivo e, uma vez mais, a mediação do representante português (que se deslocou várias vezes à Alemanha para reforçar contactos locais com a CT de Osnabruck) também. Esta medida poderá, inclusive, ter implicações na futura organização dos turnos da fábrica da Autoeuropa: A Autoeuropa está bem, mas o parque industrial à sua volta não. Nós temos tido a funcionar dois turnos, mas um terço das pessoas de um dos turnos terá de ir para a Alemanha. E outro terço terá provavelmente que reforçar o turno que fica a trabalhar só de manhã, porque agora fazem 230 carros e passarão a fazer 313 (representante português do CEE do grupo VW, entrevista, 22.04.2016).
} 
Hermes Augusto Costa é Doutor em Sociologia (FEUC) e Professor Auxiliar com agregação da Faculdade de Economia e Pesquisador do Centro de Estudos Sociais, da Universidade de Coimbra, Portugal.\Shermes@fe.uc.pt

\section{Referências}

1. ANTUNES, R. Os sentidos do trabalho: ensaio sobre a afirmação e a negação do trabalho. Coimbra: Almedina, 2013.

2. BERNACIAK, M.; GUMBRELL-MCCORMICK, R.; HYMAN, R. European trade unionism: from crisis to renewal? (report 133). Bruxelas: European Trade Union Institute, 2014.

3. BICKNELL, H. Ethno-, poly- and Eurocentric European Works Councils. How does German involvement influence their identity? In: WHITTALL, M. et al. (orgs.). Towards a European Labour Identity. The case of European Works Councils. Londres: Routledge, 2007, p. 111-131.

4. BUSCHAK, W. European works councils open new horizons. Transfer - European Review of Labour and Research, v. 1, n. 1, 1995, p. 133-135.

5. COSTA, H. A. Saving jobs, protecting rights: the Autoeuropa Agreement. Transfer - European Review of Labour and Research, v. 10, 2004, p. 123-125.

6. COSTA, H. A. Sindicalismo global ou metáfora adiada? Discursos e práticas transnacionais da CGTP e da CUT. Porto: Afrontamento, 2008, 347 pp.

7. COSTA, H. A. European works councils between formal requirements and good practices: the potential for further development based on evidence from Portugal, Transfer - European Review of Labour and Research, v. 19, n. 4, 2013, p. 553-567.

8. COSTA, H. A.; ARAÚJO, P. As vozes do trabalho nas multinacionais: o impacto dos Conselhos de Empresa Europeus em Portugal. Coimbra: Almedina/CES, 2009, 223 pp. [Prémio Agostinho Roseta/6a edição]

9. COSTA, H. A.; COSTA, P. R. Conselhos de Empresa Europeus: um estudo dos setores metalúrgico, químico e financeiro em Portugal. Coimbra: Imprensa da Universidade de Coimbra, 2014.

10. DA COSTA, I.; REHFELDT, U. Syndicats et Firmes Américaines dans I'Espace Social Européen: des Comités d'Entreprises Européens aux Comités Mondiaux. Rapport pour le Commissariat Général du Plan. Noisy-le-Grand: Centre d'Étude de l'Emploi, 2006. 
11. DE SPIEGELAERE, S. Too little, too late? Evaluating the European Works Councils recast Directive (report 138). Bruxelas : European Trade Union Institute, 2015.

12. DE SPIEGELAERE, S.; JAGODZINSKI, R. European Works Councils and SE Works Councils - facts and figures. Bruxelas: European Trade Union Institute, 2015.

13. ESTANQUE, E.; COSTA, H. A. Labour relations and social movements. In: ERASGA, D. (ed.). Sociological Landscapes: Theories, Realities and Trends. Rijeka/Croacia: INTECH/ Open Access Publishing, 2012, p. 257-282. Disponível em: http://www.intechopen.com/articles/show/title/labour-relations-and-socialmovements. Acesso em 10 dez 2016.

14. ESTANQUE, E.; COSTA, H. A.; SILVA, M. C. O futuro do sindicalismo na representação sociopolítica. In: FREIRE, A. (org.). O futuro da representação política democrática. Lisboa: Nova Vega, 2015, p. 119-142.

15. FREGE, C.; KELLY, J. (eds.). Varieties of unionism: strategies for union revitalization in a globalizing economy. Oxford. Oxford University Press, 2004.

16. GUMBRELL-MCCORMICK, R.; HYMAN, R. Trade unions in Western Europe: hard times, hard choices. Oxford: Oxford University Press, 2013.

17. HALL, P. A.; SOSKICE, D. (eds.). Varieties of Capitalism: The Institutional Foundations of Comparative Advantage. Oxford: Oxford University Press, 2001.

18. HYMAN, R. National industrial relations systems and transnational challenges: an essay in review. European Journal of Industrial Relations, v. 5, n. 1, 1999, p. 89-110.

19. HYMAN, R. European integration and industrial relations: a case of variable geometry ?. In: WATERMAN, P.; WILLS, J. (orgs.). Place, space and the new labour internationalisms. Oxford: Blackwell, 2001, p. 164-179.

20. LAULOM, S.; DORSSEMONT, F. Fundamental principles of EWC Directive 2009/38/EC. In: JAGODZINSKI, R. (ed.). Variations on a theme? The implementation of EWC recast Directive. Bruxelas: European Trade Union Institute, 2015, p. 33-67.

21. LECHER, W.; PLATZER, H-W.; RÜB, S.; WEINER, K-P. The establishment of European Works Councils: from information committee to social actor. Aldershot: Ashgate, 1999.

22. MILLER, D. Towards a "European" works council. Transfer - European Review of Labour and Research, v. 5,n. 3, 1999, p. 344-365.

23. SANTOS, B.de S. Toward a new common sense: law, science and politics in the paradigmatic transition. Londres: Routledge, 1995. 
24. SPEIDEL, F. The "Volkswagen Law" - guarantor of extended co-determination rights and international trade union solidarity. Transfer - European Review of Labour and Research, v. 18, n. 4, 2012, p. 497-501.

25. STEIERT, R.; UHL, H-J.; BRÜNING, M. A social charter for Volkswagen: a new milestone in industrial relations. Transfer - European Review of Labour and Research, v. 8, n. 4, 2002, p. 711-714.

26. TELLJOHANN, V. The European Works Councils - a role beyond the EC Directive? Transfer - European Review of Labour and Research, v. 1, n.5, 2005, p. 81-96.

27. TELLJOHANN, V.; DA COSTA, I.; MÜLLER, T.; REHFELDT, U.; ZIMMER, R. European and international framework agreements: Practical experiences and strategic approaches. Luxemburgo: European Foundation for the Improvement of Living and Working Conditions, 2009.

28. WADDINGTON, J. European Works Councils: a transnational industrial relations Institution in the making. Londres: Routledge, 2011.

29. WHITTALL, M.; KNUDEN, H.; HUIJGEN, Fred (orgs.). Towards a European Labour Identity. The case of European Works Councils. Londres: Routledge, 2007.

30. WILLS, J. Great expectations: three years in the life of a European Works Council, European Journal of Industrial Relations, v. 6, n. 1, 2000, p. 83-105.

31. WILLS, J. Uneven geographies of capital and labour: the lessons of European Works Councils. In:WATERMAN, P.;WILLS, J. (orgs.), Place, space and the new labour internationalisms. Oxford: Blackwell, 2001, p. 180-205.

32. VW AG; CT EUROPEIA DO GRUPO VW; CT MUNDIAL DO GRUPO VW; FITIM. Carta das relações laborais no Grupo Volkswagen. Zwickau, 29.10.2009, 1-7 (mimeo).

Recebido em: 27.12.2016 Aceito em: 09.02.2017 